\title{
The Study of Critical Heat Flux in Upflow Boiling Vertical Round Tube under High Pressure
}

\author{
Wei Liu $\mathbb{D}^{1},{ }^{1}$ Jianqiang Shan $\mathbb{D}^{2},{ }^{2}$ Shinian Peng $\mathbb{D}^{1},{ }^{1}$ Guangming Jiang, ${ }^{1}$ and Yu Liu ${ }^{1}$ \\ ${ }^{1}$ State Key Laboratory of Reactor System Design Technology, Nuclear Power Institute of China, Chengdu 610213, China \\ ${ }^{2}$ School of Nuclear Science and Technology, Xian Jiaotong University, Xian 710049, China \\ Correspondence should be addressed to Wei Liu; liuwei0958@126.com
}

Received 20 February 2019; Revised 13 April 2019; Accepted 5 May 2019; Published 4 June 2019

Academic Editor: Rafa Miró

Copyright (c) 2019 Wei Liu et al. This is an open access article distributed under the Creative Commons Attribution License, which permits unrestricted use, distribution, and reproduction in any medium, provided the original work is properly cited.

\begin{abstract}
The Critical Heat Flux (CHF) prediction under high pressure condition, even close to the vicinity of the critical pressure of water, is an important issue. Although there are many empirical CHF correlations, most of them have covered the pressure under $15 \mathrm{MPa}$. In this study, based on the CHF experiment database of upflow boiling in vertical round tube from 15MPa to the vicinity of the critical pressure of water, the Katto, Bowring, Hall-Mudawar, Alekseev correlations, and Groeneveld LUT-2006 are comparatively studied. With an error analysis of the predicted CHF to the experiment database, the prediction capability and the applicability of these correlations are evaluated and the parametric trends of CHF varying with pressure from 15MPa to critical pressure are proposed. Simultaneously, according to the characteristics of Departure from Nucleate Boiling (DNB) type CHF under high pressure condition, the constitutive correlations of Weisman \& Pei model are proposed. The prediction results of three entrainment and deposition correlations of Kataoka, Celata, and Hewitt corresponding to the Dry-Out (DO) type CHF are analyzed. Based on the two improved models above, a comprehensive CHF mechanistic model under high pressure condition combining the DNB and DO type CHF is established. The verification based on the experiment database of upflow boiling in vertical round tube and the parametric trends analysis of CHF varying with thermal-hydraulic and geometric parameters are carried out. Findings of this study have a positive effect on further development of CHF prediction method for universal CHF mechanism, especially under high pressure region.
\end{abstract}

\section{Introduction}

The accurate prediction of critical heat flux (CHF) in flow boiling is important in the design and safety analysis of nuclear reactor. The occurrence of CHF results in a sharp degradation of the convective heat transfer between the fuel rod cladding and the reactor coolant which may result in cladding failure.

The supercritical water cooled reactor (SCWR) has high operating pressure and temperature, and, during sliding pressure start-up procedure from subcritical pressure to supercritical pressure, the thermophysical properties and transport properties of the coolant in the core would change greatly [1]. Thus, the CHF prediction under high pressure condition, even close to the vicinity of the critical pressure of water, is an important issue for SCWR.
Although the CHF phenomenon has been extensively investigated over the last five decades, knowledge of the physical nature of $\mathrm{CHF}$ is still incomplete and the mechanisms of boiling crisis are still not well understood.

Methods for predicting CHF can be categorized as empirical correlations, look-up tables, and mechanistic models. According to the statistics [2], the number of published CHF correlations for water-cooled round tubes has increased to well over 500 and there are also over 50 CHF models available. Based on the difference of flow regime and heat transfer characteristics on the occurrence of CHF, the boiling crisis can be generally divided into DNB (Departure from Nucleate Boiling) type and DO (Dry-Out) type [3].

Although there are many empirical CHF correlations, there is no valid and accurate CHF correlation verified by experiment database in the range from $15 \mathrm{MPa}$ to the vicinity 
TABLE 1: CHF experiment database under high pressure region.

\begin{tabular}{lcc}
\hline Reference & Time & No. of data \\
\hline McGill \& Sibbitt [17] & 1951 & 9 \\
Epstein et al. [18] & 1956 & 90 \\
Ornatskii \& Kichigin [19] & 1962 & 31 \\
Ornatskii [20] & 1963 & 69 \\
Alekseev et al. [21] & 1964 & 508 \\
Bailey \& Lee [22] & 1969 \\
Peskov et al. [23] & 1969 \\
Zenkevich et al. [24] & 1969 \\
Zenkevich et al. [25] & 1971 \\
Zenkevich [26] & 1974 \\
Belyakov et al. [27] & 1976 \\
Smolin et al. [28] & 1979 \\
Williams \& Beus [29] & 1980 \\
Kirillov et al. [30] & 1984 \\
Groeneveld [31] & 1985 \\
Yin et al. [32] & 1988 \\
Soderquist [33] & 1994 \\
Mudawar \& Bowers [34] & 1999 & 1298 \\
Total & & 152 \\
\hline
\end{tabular}

of critical pressure, in which the parametric trend of $\mathrm{CHF}$ varying with pressure is also unknown.

Furthermore, different $\mathrm{CHF}$ mechanistic models usually are proposed for specific flow regime, and one CHF model is only effective in one flow regime resulting in a narrow prediction scope. This cannot satisfy the prediction of $\mathrm{CHF}$ when different flow regimes appear successively in the same channel.

In this study, based on the CHF experiment database of upflow boiling in vertical round tube from 15MPa to the vicinity of the critical pressure of water, the prediction capability, and the applicability of Katto [4], Bowring [5], HallMudawar [6], Alekseev [7] correlations, and LUT-2006 [8] will be evaluated. The parametric trend of $\mathrm{CHF}$ varying with pressure from $15 \mathrm{MPa}$ to the vicinity of critical pressure will be discussed. Simultaneously, combining the DNB and DO type CHF mechanism, a comprehensive CHF model under high pressure condition will be established. Finally, the verification of the CHF mechanistic model based on the experiment database and the parametric trends analysis of CHF varying with thermal-hydraulic and geometric parameters will be carried out.

\section{The Experiment Database}

Based on the existing CHF database of upflow boiling vertical round tube, the evaluation and screening of experiment database are carried out. As a result, 18 different sets of CHF experiment database were obtained from 1951 to 1999, in total of 4355 data points are applied in this study. The database sources and distribution are shown in Table 1, among which 2735 experiment data points belong to the DNB type CHF of subcooled bubbly flow and 1620 experiment data points belong to the DO type CHF of saturated annular flow. Table 2 shows the experimental ranges of database.

\section{The Comparative Study of CHF Correlations}

3.1. CHF Correlations. Through the comparison and analysis of dozens of round tube CHF correlations, this study has selected the Katto [4], Bowring [5], Hall-Mudawar [6], Alekseev [7] correlations, and LUT-2006 [8] which all cover the high-pressure region for further analysis. The parameter range of each correlation is shown in Table 3.

3.2. Comparative Analysis. For analysis, the error $E$, mean error $M E$, mean absolute error $M A E$, and root mean square error $R M S$ are defined as follows:

Error E:

$$
E=\frac{q_{\mathrm{CHF}, \text { pre }}-q_{\mathrm{CHF}, \text { exp }}}{q_{\mathrm{CHF}, \exp }}
$$

Mean error $M E$ :

$$
M E=\frac{1}{N} \sum \frac{q_{\mathrm{CHF}, \mathrm{pre}}-q_{\mathrm{CHF}, \exp }}{q_{\mathrm{CHF}, \exp }} \times 100 \%
$$

Mean absolute error MAE:

$$
M A E=\frac{1}{N} \sum\left|\frac{q_{\mathrm{CHF}, \text { pre }}-q_{\mathrm{CHF}, \exp }}{q_{\mathrm{CHF}, \exp }}\right| \times 100 \%
$$

Root mean square error RMS:

$$
R M S=\sqrt{\frac{1}{N} \sum\left(\frac{q_{\mathrm{CHF}, \mathrm{pre}}-q_{\mathrm{CHF}, \exp }}{q_{\mathrm{CHF}, \exp }}\right)^{2}} \times 100 \%
$$


TABLE 2: Experimental ranges of database.

\begin{tabular}{|c|c|c|c|c|c|c|}
\hline Variable & $\Delta h_{i n}(\mathrm{~kJ} / \mathrm{kg})$ & $G\left(\mathrm{~kg} / \mathrm{m}^{2} \mathrm{~s}\right)$ & $P(\mathrm{MPa})$ & $D(\mathrm{~m})$ & $L(\mathrm{~m})$ & $x_{\mathrm{e}}$ \\
\hline \multicolumn{7}{|c|}{ The DNB type CHF } \\
\hline Maximum value & 1811 & 7530 & 21.20 & 0.016 & 7 & 0.54 \\
\hline Minimum value & 36 & 256 & 15.17 & 0.0055 & 0.0254 & -2.41 \\
\hline \multicolumn{7}{|c|}{ The DO type CHF } \\
\hline Maximum value & 1549 & 6578 & 20.10 & 0.016 & 20 & 0.97 \\
\hline Minimum value & 36 & 156 & 15.17 & 0.0055 & 0.79 & 0.02 \\
\hline
\end{tabular}

TABLE 3: Parameter ranges of CHF correlations.

\begin{tabular}{|c|c|c|c|c|c|}
\hline Variable & Katto & Bowring & Hall-Mudawar & Alekseev & LUT-2006 \\
\hline$P(M P a)$ & $0.5 \sim 20$ & $0.2 \sim 19.0$ & $1 \sim 20$ & $9.81 \sim 19.62$ & $0.1 \sim 20$ \\
\hline$G\left(k g / m^{2} \mathrm{~s}\right)$ & $10.5 \sim 8800$ & $136 \sim 18600$ & $300 \sim 30000$ & $1000 \sim 5000$ & $0 \sim 8000$ \\
\hline$x_{\mathrm{e}}$ & - & - & $-1.00 \sim-0.05$ & $0 \sim 0.4$ & $0.5 \sim 1$ \\
\hline$D(\mathrm{~m})$ & $0.001 \sim 0.038$ & $0.002 \sim 0.045$ & $0.00025 \sim 0.015$ & $0.004 \sim 0.012$ & $0.002 \sim 0.016$ \\
\hline$L(m)$ & $0.01 \sim 8.8$ & $0.15 \sim 3.7$ & $0.3 \sim 8$ & $\geqslant 0.2$ & - \\
\hline
\end{tabular}

TABle 4: Prediction error of each CHF correlation.

\begin{tabular}{lcccccc}
\hline \multirow{2}{*}{ CHF correlations } & \multicolumn{2}{c}{$M E$} & \multicolumn{2}{c}{$M A E$} & \multicolumn{2}{c}{$R M S$} \\
& $\mathrm{P}>15 \mathrm{MPa}$ & $\mathrm{P}>19 \mathrm{MPa}$ & $\mathrm{P}>15 \mathrm{MPa}$ & $\mathrm{P}>19 \mathrm{MPa}$ & $\mathrm{P}>15 \mathrm{MPa}$ & $\mathrm{P}>19 \mathrm{MPa}$ \\
\hline Katto & $14.2 \%$ & $6.7 \%$ & $15.6 \%$ & $8.0 \%$ & $23.4 \%$ & $14.1 \%$ \\
Bowring & $-14.2 \%$ & $-16.6 \%$ & $15.8 \%$ & $18.5 \%$ & $20.4 \%$ & $23.2 \%$ \\
Hall-Mudawar & $-8.3 \%$ & $-6.1 \%$ & $9.4 \%$ & $7.3 \%$ & $12.8 \%$ & $9.8 \%$ \\
Alekseev & $0.1 \%$ & $0.7 \%$ & $6.3 \%$ & $8.6 \%$ & $9.6 \%$ \\
LUT-2006 & $1.3 \%$ & $1.1 \%$ & $4.4 \%$ & $5.5 \%$ & $7.9 \%$ & $8.4 \%$ \\
\hline
\end{tabular}

where $q_{\mathrm{CHF}}$,pre is the predictive value of $\mathrm{CHF}$, while $q_{\mathrm{CHF}}$ exp is the experimental value of CHF.

3.2.1. Prediction Error Analysis. In evaluation of the correlations and LUT-2006 accuracy, the Heat Balance Method (HBM) has been used. The prediction errors of Katto, Bowring, Hall-Mudawar, Alekseev correlations, and LUT2006 are shown in Table 4. It demonstrates that the prediction errors of LUT-2006 and Alekseev correlation are relatively smaller in the high pressure region above $15 \mathrm{MPa}$, while the prediction errors of Katto and Bowring correlation are larger. Although the Hall-Mudawar correlation is only applicable for subcooled boiling, its prediction error is also not large which belongs to the middle level between the LUT-2006 and Alekseev and Katto and Bowring correlations.

The prediction errors of Katto, Alekseev correlation, and LUT-2006 varying with pressure are shown in Figure 1.

It indicates that, in the range of $19 \mathrm{MPa}$ to $20.3 \mathrm{MPa}$, the Katto correlation overpredicts the experimental value, but when the pressure is higher than $20.3 \mathrm{MPa}$, the predictive value and the experimental value become closer.

Although the RMS errors of the predictive value and the experimental value for Alekseev correlation and LUT-2006 are smaller, in the range of $20.3 \mathrm{MPa}$ to $21.3 \mathrm{MPa}$, these two correlations underpredict the experimental values.

When the pressure is higher than $21.3 \mathrm{MPa}$ to the vicinity of critical pressure, the prediction capabilities of the three correlations could not be evaluated due to the lack of CHF experiment database.

3.2.2. Parametric Trend Analysis. In the vicinity of critical pressure, the physical properties and heat transfer characteristics of water have greatly changed; consequently, the $\mathrm{CHF}$ has become more sensitive to pressure. For simplicity, Figure 2 shows the predictive value of different CHF correlation varying with pressure when other parameters $G, \Delta h_{i n}$, $D$, and $L$ are fixed constant.

Combined with the error comparison analysis in Section 3.2.1, the parametric trend of CHF in high pressure region can be summarized as follows (identified by the red dotted line on Figure 2): in the range of $19 \mathrm{MPa}$ to $20.3 \mathrm{MPa}$, it is close to the prediction trend of LUT-2006; when the pressure is higher than $20.3 \mathrm{MPa}$, it should be closer to the prediction trend of Katto correlation; and when approaching critical pressure, the CHF quickly goes down to zero.

\section{The Development of CHF Mechanistic Model}

4.1. DNB Type CHF Mechanistic Model. Weisman \& Pei [9] developed a phenomenological model for $\mathrm{CHF}$ at low void fractions or subcooled conditions. The model is generally applicable in the bubbly flow regime, where it is assumed that a bubbly layer exists adjacent to the heater surface. At 


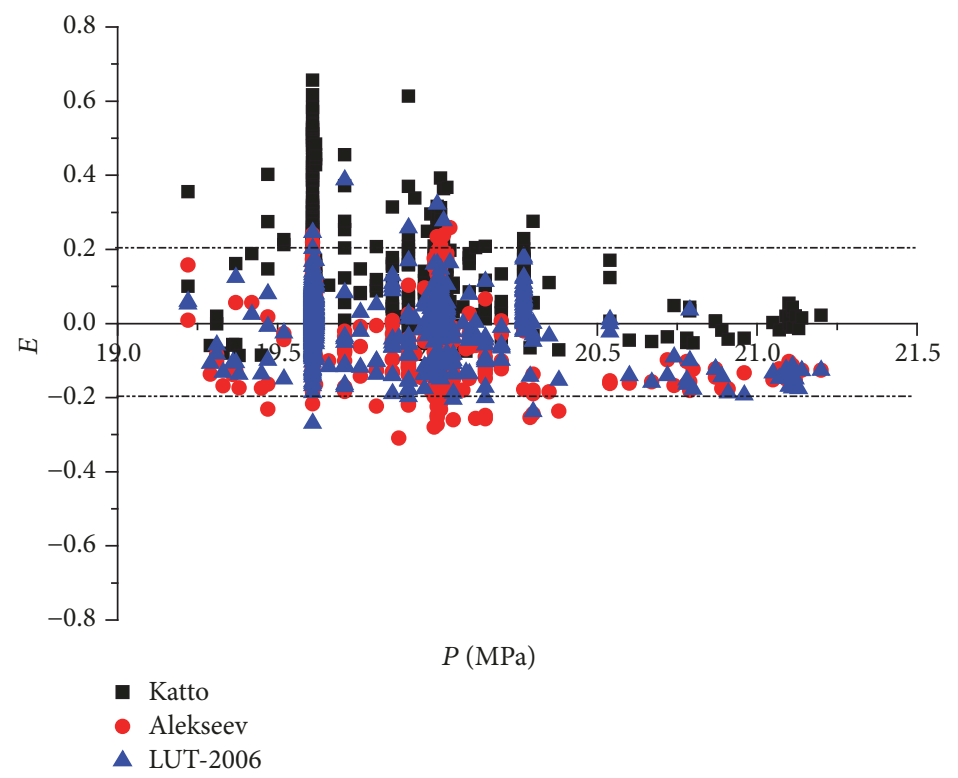

FIGURE 1: Prediction error of Katto, Alekseev, and LUT-2006 varying with pressure.

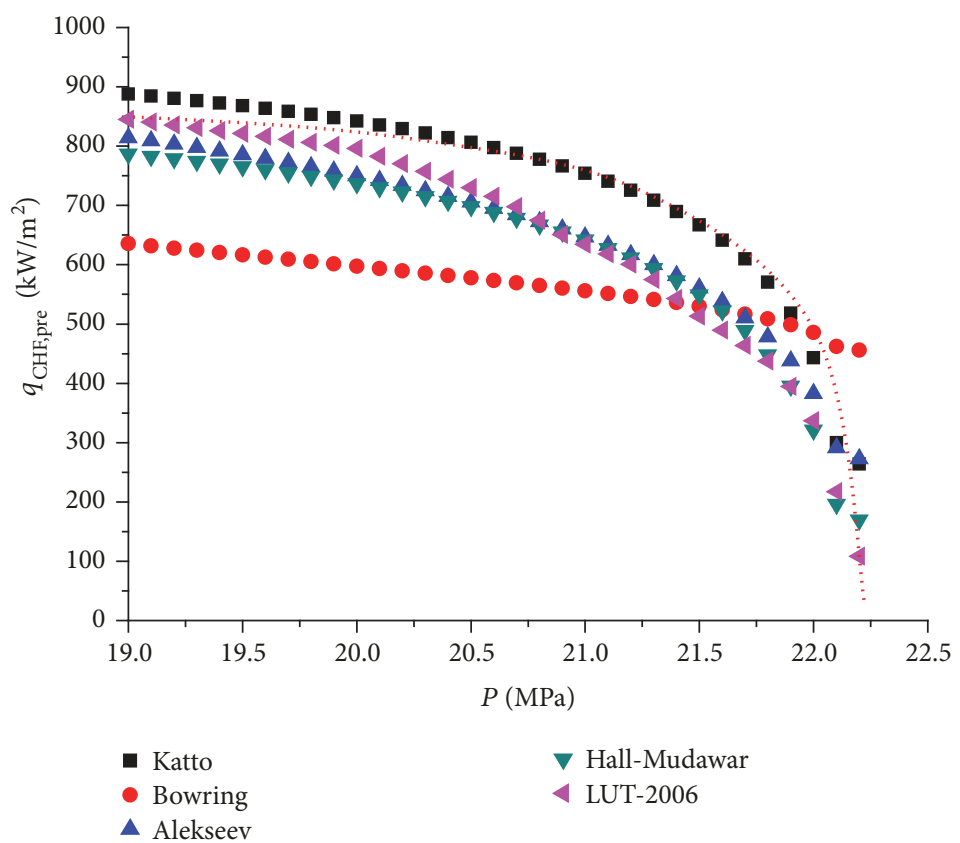

Figure 2: $\mathrm{q}_{C H F}$ as a function of pressure ( $G=2000 \mathrm{~kg} / \mathrm{m}^{2} \mathrm{~s}, \triangle h_{\text {in }}=450 \mathrm{~kJ} / \mathrm{kg}, D=0.013 \mathrm{~m}, L=3 \mathrm{~m}$ ).

high heat fluxes, the local vapour generation rate becomes so high that it prevents the liquid from reaching and cooling the heated surface, leading to CHF, as shown in Figure 3.

Weisman \& Pei utilized a number of assumptions in the development of the model and obtained

$$
\frac{q^{\prime \prime} D N B}{h_{f g} G^{\prime}}=\left(x_{2}-x_{1}\right)\left(\frac{h_{f}-h_{l d}}{h_{l}-h_{l d}}\right)
$$

The quantity $G^{\prime}$ represents the total mass velocity into the bubbly layer, due to turbulent interchange at the edge of the bubbly layer.

$$
G^{\prime}=\psi I_{b} G
$$

The parameter $I_{b}$ represents the turbulent intensity at the bubbly layer/core interface.

$$
I_{b}=0.462 k^{0.6} \operatorname{Re}^{-0.1}\left(\frac{D_{b}}{d}\right)^{0.6}\left[1+\frac{a\left(\rho_{l}-\rho_{v}\right)}{\rho_{v}}\right]
$$




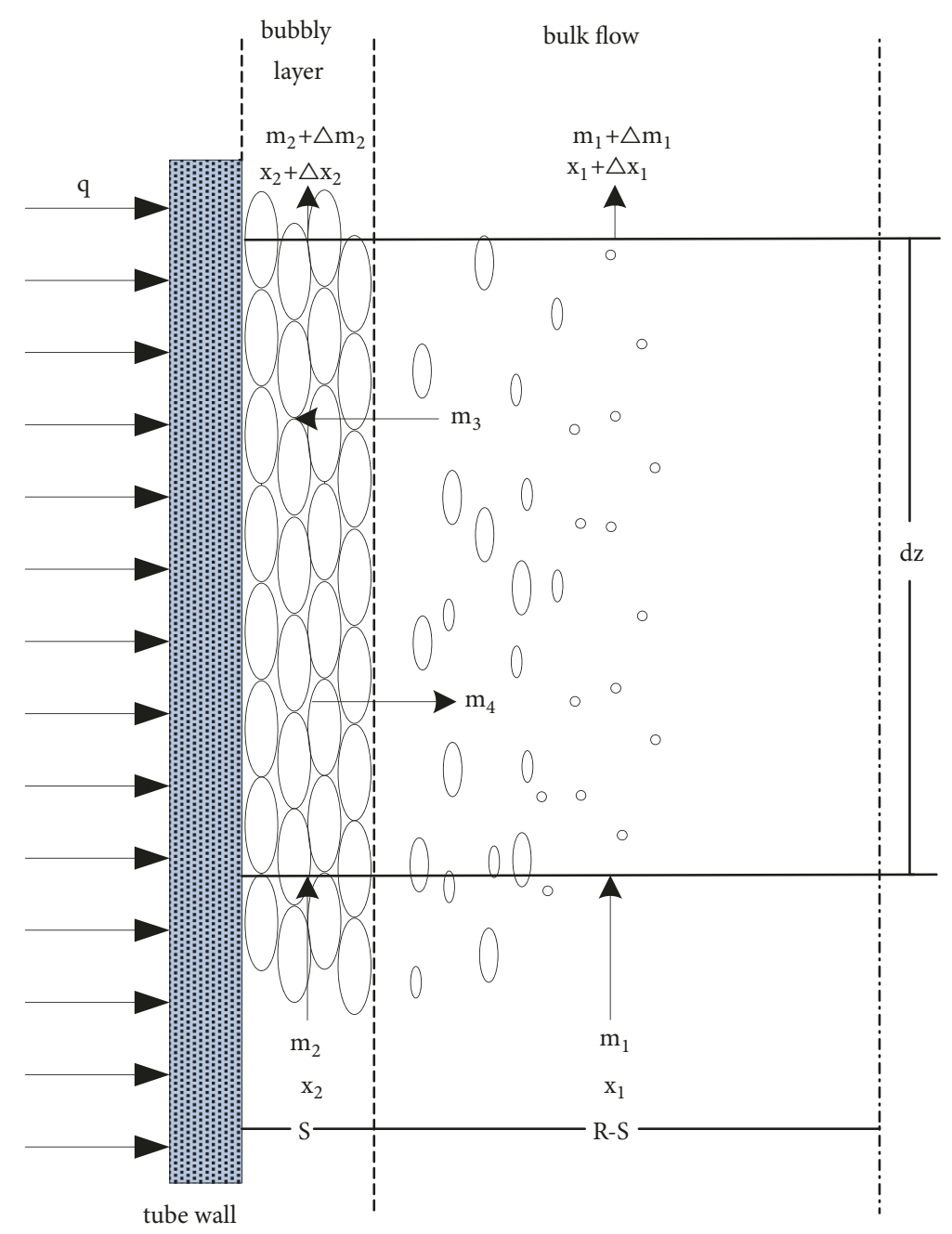

Figure 3: Schematic diagram of Weisman \& Pei model.

The parameters $k(=2.4)$ and $a$ (which depends on the mass velocity) were empirically determined by fitting a large number of uniform heat flux experiment data. Therefore, the validity of the Weisman \& Pei model is limited by the ranges of the databases, from which these empirical coefficients were obtained.

In this study, based on the experiment database of upflow boiling in vertical round tube under high pressure condition, the new parameter $k=1.8$ is obtained and parameter $a$ is associated with the velocity change and pressure effect (through $\left.\rho_{v} / \rho_{l}\right)$.

The final expression is as follows:

$a$

$$
= \begin{cases}1.23-1.25 u+5.47 \times\left(\frac{\rho_{v}}{\rho_{l}}\right)^{2.3} & u<1.2 \mathrm{~m} / \mathrm{s} \\ -0.15 \times(3-u)+5.47 \times\left(\frac{\rho_{v}}{\rho_{l}}\right)^{2.3} & 1.2 \mathrm{~m} / \mathrm{s} \leq u<3 \mathrm{~m} / \mathrm{s} \\ 5.47 \times\left(\frac{\rho_{v}}{\rho_{l}}\right)^{2.3} \times\left(\frac{u}{3}\right)^{0.3} & u \geq 3 \mathrm{~m} / \mathrm{s}\end{cases}
$$

4.2. DO Type CHF Mechanistic Model. The majority of the available annular flow DO models are based on that of Whalley et al. [10] which is a three-field model representing two-phase interactions between vapour, liquid film, and entrained droplets, as shown in Figure 4. The difference from each model is in the constitutive correlations representing the mechanisms of entrainment and deposition. In fact, it is these correlations that distinguish one phenomenological DO model from another, since the basic conservation equations are the same for any DO model in the annular flow regime.

In this study, three different entrainment and deposition correlations of Kataoka, Celata, and Hewitt are compared and analyzed.

The droplet deposition rate is calculated from

$$
D=k C
$$

where $C$ is the concentration of droplets in the vapour core and $k$ is the deposition mass transfer coefficient.

(1) Kataoka Correlation. Kataoka et al. [11] developed correlations for entrainment rate covering both entrance region and 


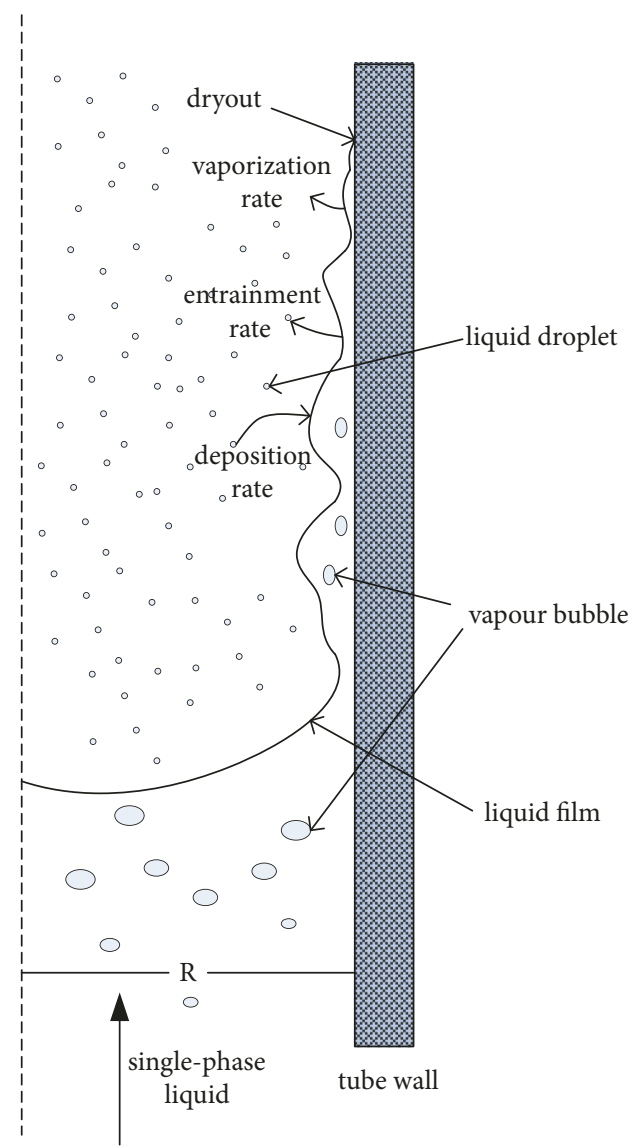

FIGURE 4: Schematic diagram of DO model.

equilibrium region from a simple model in collaboration with data.

The deposition mass transfer coefficient $\mathrm{k}$ is determined by Paleev \& Filippovich correlation [12].

$$
\frac{k}{j_{g}}=0.022 \operatorname{Re}_{g}^{-0.25}\left(\frac{C}{\rho_{f}}\right)^{-0.26}\left(\frac{\rho_{g}}{\rho_{f}}\right)^{0.26}
$$

The entrainment fraction is calculated by Ishii \& Mishima [13] correlation which was developed based on the mechanistic model of shearing-off of roll wave crest by a streaming gas.

(2) Celata Correlation. In developing of Celata et al.s [14] DO type $\mathrm{CHF}$ model, liquid film flow rate is obtained by a balance of liquid entrainment and droplet deposition.

The droplets deposition rate is calculated with the equation given by Kataoka \& Ishii [15].

$$
\frac{d D}{\mu_{l}}=0.22 \operatorname{Re}_{l}^{0.74}\left(\frac{\mu_{v}}{\mu_{l}}\right)^{0.26} E^{0.74}
$$

The droplets entrainment rate is calculated considering the contribution of two different mechanisms of droplets formation: breakup of disturbance waves $\left(E_{w}\right)$ and boiling in the liquid film $\left(E_{B}\right)$.

$$
E=E_{w}+E_{B}
$$

(3) Hewitt Correlation. Hewitt et al. [16] derived improved models for deposition and entrainment in annular flow. The new models successfully predicted a wide range of equilibrium and non-equilibrium data.

The correlation for the deposition rate coefficient is as follows:

$$
k= \begin{cases}0.18 \sqrt{\frac{\sigma}{\rho_{v} d}}, & \frac{C}{\rho_{v}} \leq 0.3 \\ 0.083 \sqrt{\frac{\sigma}{\rho_{v} d}}\left(\frac{C}{\rho_{v}}\right)^{-0.65}, & \frac{C}{\rho_{v}}>0.3\end{cases}
$$

The entrainment correlation is

$$
\begin{aligned}
& \frac{E}{G_{v}} \\
& = \begin{cases}5.75 \times 10^{-5}\left[\left(G_{L F}-G_{L F C}\right)^{2} \frac{d \rho_{l}}{\sigma \rho_{v}^{2}}\right]^{0.316}, & G_{L F}>G_{L F C} \\
0, & G_{L F} \leq G_{L F C}\end{cases}
\end{aligned}
$$

where $G_{L F C}$ is the critical film mass velocity for the onset of entrainment.

4.3. The Comprehensive CHF Mechanistic Model. According to the two improved $\mathrm{CHF}$ mechanistic model types above, 


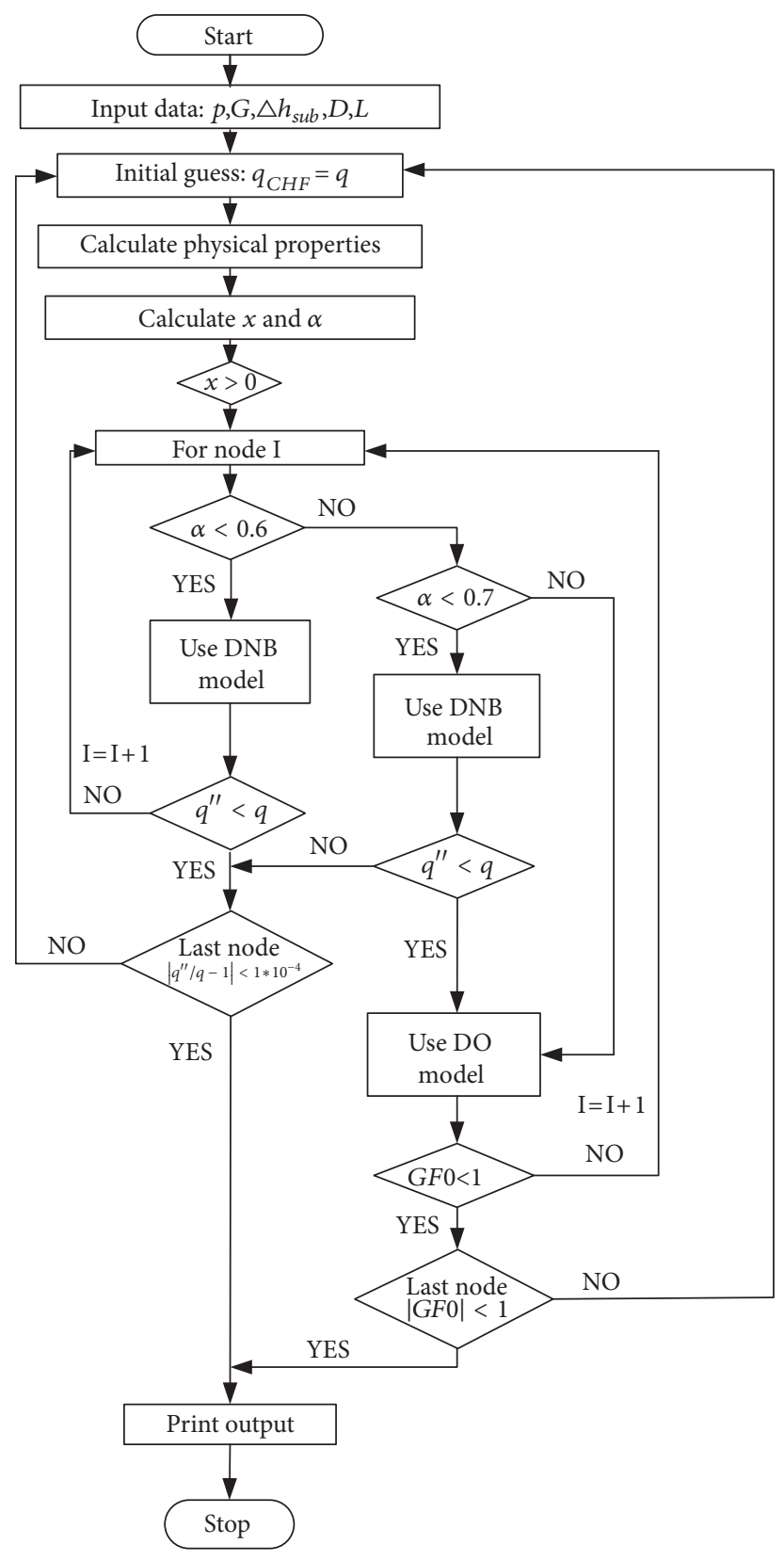

FIGURE 5: Flow chart of detailed calculation.

a comprehensive CHF mechanistic model under high pressure condition combining the DNB and DO type CHF is established. The detailed calculation process of the present mechanistic model is shown in Figure 5.

The void fraction $\alpha_{\text {ann }}$ is the transition point of bubble flow and annular flow. When $\alpha<\alpha_{\text {ann }}$, the flow regime is bubble flow and the CHF is calculated by the DNB model. When $\alpha>\alpha_{\text {ann }}$, the flow regime is annular flow and the CHF calculation is divided into two situations: (1) if $\alpha<\alpha_{\mathrm{DNB}}$, the DNB model is still used; (2) if no DNB occurrence or $\alpha>\alpha_{\mathrm{DNB}}$, then the DO model is used to calculate the flow rate of liquid film.

\subsection{Results Analysis}

4.4.1. Prediction Error Analysis. In evaluation of the present mechanistic model accuracy, the Heat Balance Method (HBM) has been used. Table 5 shows the prediction error of the present mechanistic model for the whole experiment database and the DNB type CHF, respectively. Table 6 shows the prediction results of three different entrainment and deposition correlations.

It demonstrates that the present mechanistic model is applicable for the CHF prediction of upflow boiling in vertical round tube under high pressure conditions, and the RMS 
TABLE 5: Prediction error of the present mechanistic model.

\begin{tabular}{|c|c|c|c|c|c|c|}
\hline Data points & Maximum error & Minimum error & The fraction of error within $10 \%$ & The fraction of error within $20 \%$ & $M E$ & $R M S$ \\
\hline \multicolumn{7}{|c|}{ The whole experiment database } \\
\hline 4355 & $44.2 \%$ & $-38.9 \%$ & $82.2 \%$ & $96.0 \%$ & $0.5 \%$ & $8.3 \%$ \\
\hline \multicolumn{7}{|c|}{ The DNB type CHF } \\
\hline 2735 & $44.5 \%$ & $-46.0 \%$ & $85.8 \%$ & $96.4 \%$ & $0.6 \%$ & $7.0 \%$ \\
\hline
\end{tabular}

TABLE 6: Prediction results of three different entrainment and deposition correlations.

\begin{tabular}{lccccccc}
\hline $\begin{array}{l}\text { Data } \\
\text { points }\end{array}$ & $\begin{array}{c}\text { Different } \\
\text { correlation }\end{array}$ & $\begin{array}{c}\text { Maximum } \\
\text { error }\end{array}$ & $\begin{array}{c}\text { Minimum } \\
\text { error }\end{array}$ & $\begin{array}{c}\text { The fraction } \\
\text { of error } \\
\text { within 10\% }\end{array}$ & $\begin{array}{c}\text { The fraction } \\
\text { of error } \\
\text { within 20\% }\end{array}$ & $M E$ \\
\hline \multirow{3}{*}{1620} & Kataoka & $34.7 \%$ & $-38.9 \%$ & $72.1 \%$ & $94.5 \%$ & $0.4 \%$ & $9.9 \%$ \\
& Celata & $40.3 \%$ & $-61.3 \%$ & $36.2 \%$ & $49.0 \%$ & $27.9 \%$ & $40.1 \%$ \\
& Hewitt & $14.4 \%$ & $-86.1 \%$ & $2.9 \%$ & $15.8 \%$ & $40.6 \%$ \\
\hline
\end{tabular}

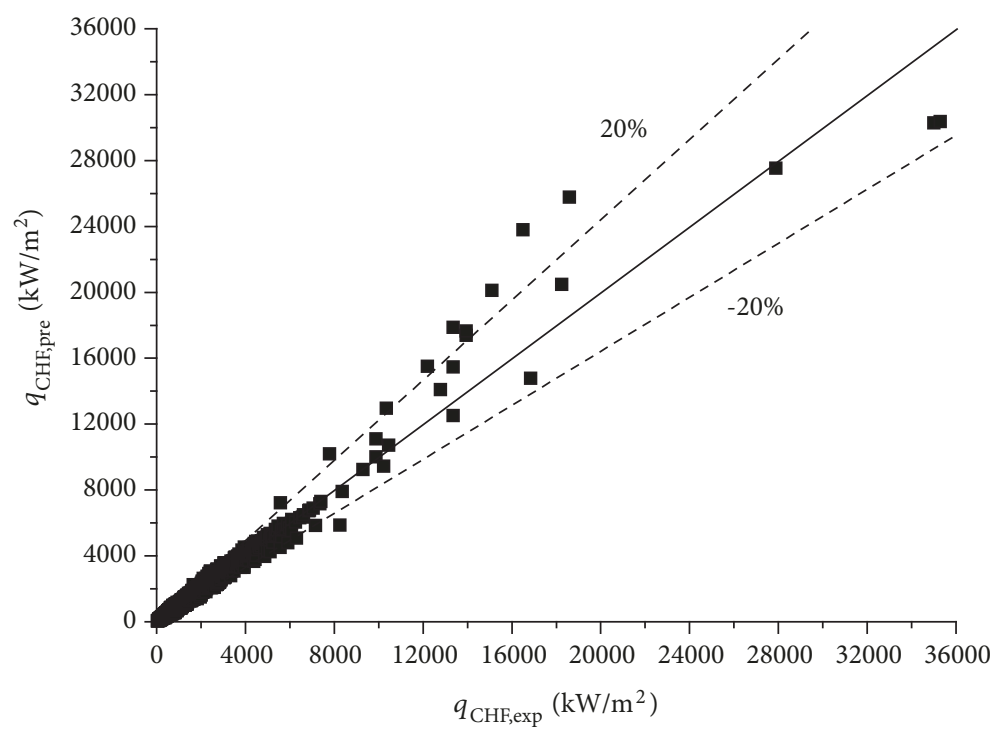

FIgURE 6: Predicted CHF as a function of measured CHF.

of the DNB model is the lowest. For the DO type CHF prediction, the results of the Kataoka correlation are the best.

The comparison of predicted $\mathrm{CHF}$ and measured $\mathrm{CHF}$ is shown in Figure 6.

Figure 7 shows the prediction results of the present mechanistic model, Katto correlation, and LUT-2006. It indicates that the present mechanistic model is more accurate than the other two predictions, especially when pressure is higher than 19MPa.

4.4.2. Continuity of the Developed Model. The significant characteristic of the present mechanistic model is that, for a certain flow regime, it can automatically judge and select the particular model to calculate the $\mathrm{CHF}$ value.

Figures 8 and 9 show the continuous variation of DNB and DO type CHF predicted by the present mechanistic model with mass velocity and inlet subcooled enthalpy, respectively. It indicates that the DO type $\mathrm{CHF}$ occurs at low mass velocity and low inlet subcooled enthalpy. With the increase of mass velocity and inlet subcooled enthalpy, the DNB type CHF occurs. In this study, the DNB and DO type CHF can be smoothly joined together with the present mechanistic model.

4.4.3. Parametric Trend Analysis. The parametric trends of the $\mathrm{CHF}$ vary according to the thermal-hydraulics conditions determined by the combination of the various ranges of pressure, mass velocity, inlet subcooled enthalpy, and geometric parameters.

The CHF predicted by the present mechanistic model as a function of independent variables pressure, mass velocity, inlet subcooled enthalpy, tube diameter, and tube length are shown in Figures 10-14, respectively. It indicates that the predicted $\mathrm{CHF}$ decreases with the increase of pressure. When approaching the critical pressure, CHF rapidly drops to zero. The predicted CHF almost linearly increases with the increase of mass velocity and inlet subcooled enthalpy. As for the geometric parameters, the predicted CHF increases with the 


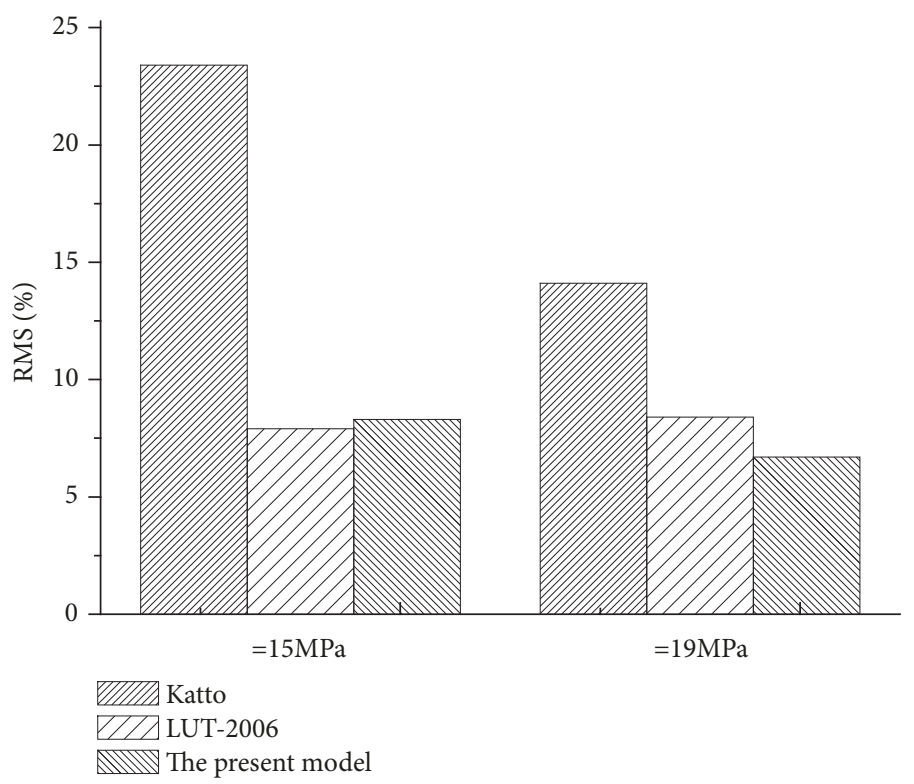

FIGURE 7: RMS histograms of each method.

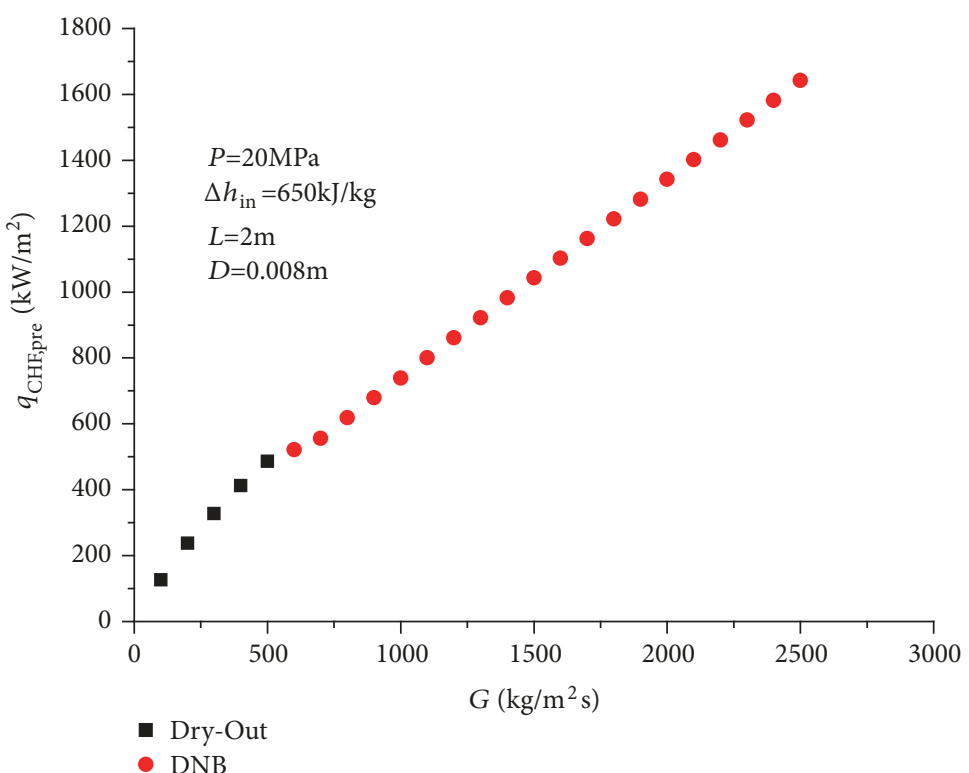

FIGURE 8: Continuous variation of CHF with mass velocity.

increase of tube diameter and decreases with the increase of tube length. While beyond the threshold of $D$ or $L$, the influence of the $D$ and $L$ is small.

\section{Conclusion}

In this study, based on the CHF experiment database of upflow boiling in vertical round tube from $15 \mathrm{MPa}$ to the vicinity of the critical pressure of water, five CHF correlations under high pressure conditions are selected and the prediction results have been comparatively analyzed.
Simultaneously, a comprehensive CHF mechanistic model under high pressure condition combined the DNB and DO type CHF has been established. The verification of the present mechanistic model based on the experiment database and the parametric trends analysis of CHF varying with thermalhydraulic and geometric parameters have been carried out. The conclusions can be briefly summarized as follows:

(1) In the high pressure range of $15 \mathrm{MPa}$ to the vicinity of critical pressure, the Alekseev correlation and LUT2006 are recommended for their smaller prediction error to predict $\mathrm{CHF}$ in round tube. 


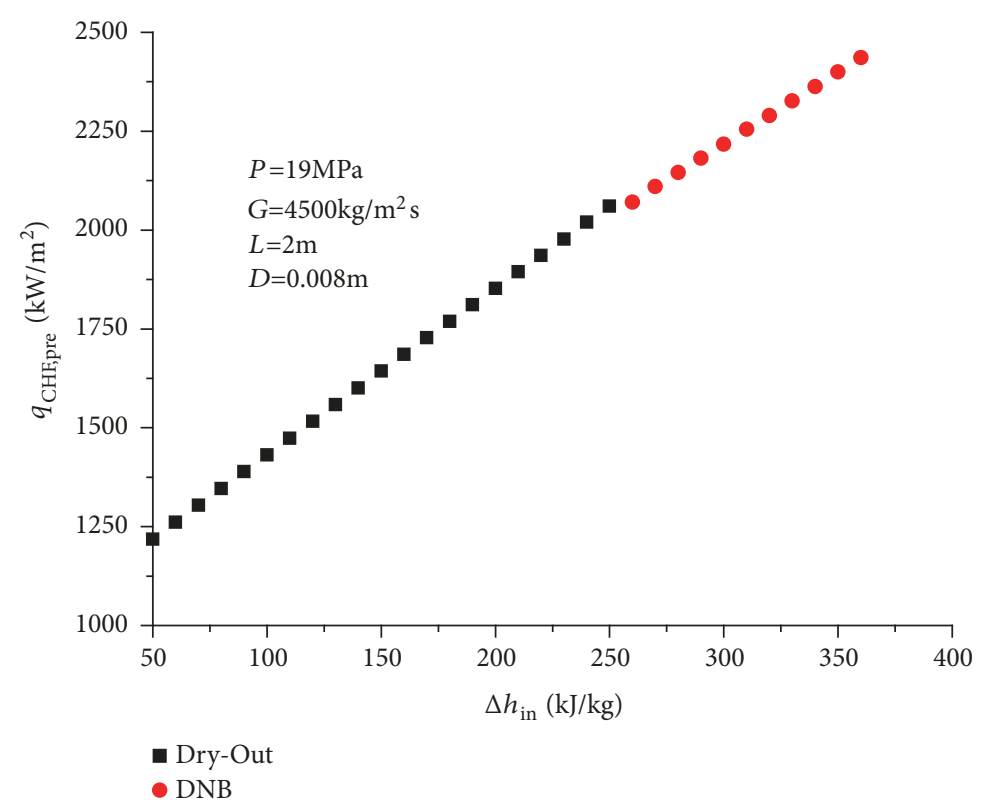

FIGURE 9: Continuous variation of CHF with inlet subcooled enthalpy.

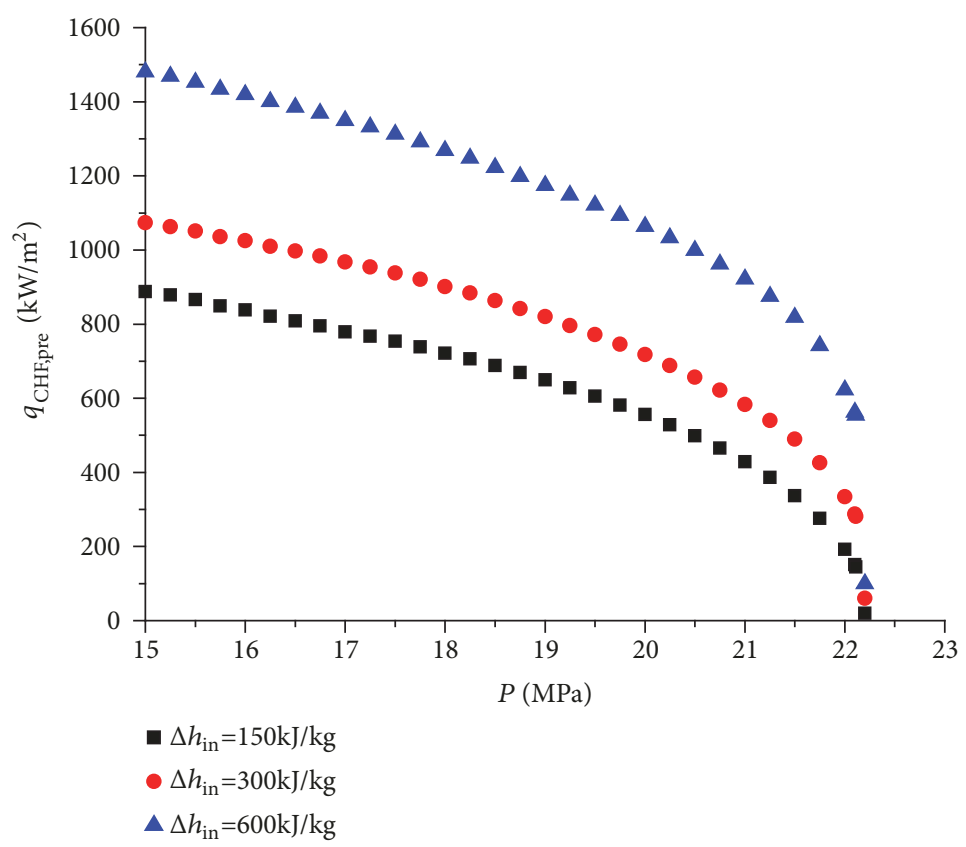

FIgURE 10: CHF as a function of pressure $\left(G=1000 \mathrm{~kg} / \mathrm{m}^{2} \mathrm{~s}\right)$.

(2) The parametric trend of CHF varying with pressure in the range from $15 \mathrm{MPa}$ to the vicinity of critical pressure is obtained. In the transition point of 20.3MPa, the CHF parametric trend varies from the LUT-2006 curve to the Katto correlation curve, and when approaching critical pressure, the CHF quickly goes down to zero.

(3) The present mechanistic model is applicable for the CHF prediction of upflow boiling in vertical round tube under high pressure conditions, and the fraction of error within $\pm 20 \%$ is $96.0 \%$ of total data points. For the DO type CHF prediction, the prediction results of Kataoka correlation are more accurate than Celata and Hewitt methods, and the whole RMS is $9.9 \%$.

(4) For a specific flow regime, the present mechanistic model can automatically judge and select the particular model to calculate the CHF value, which can smoothly join the DNB and DO type CHF.

(5) The parametric trends of predicted CHF varying with thermal-hydraulic and geometric parameters are 


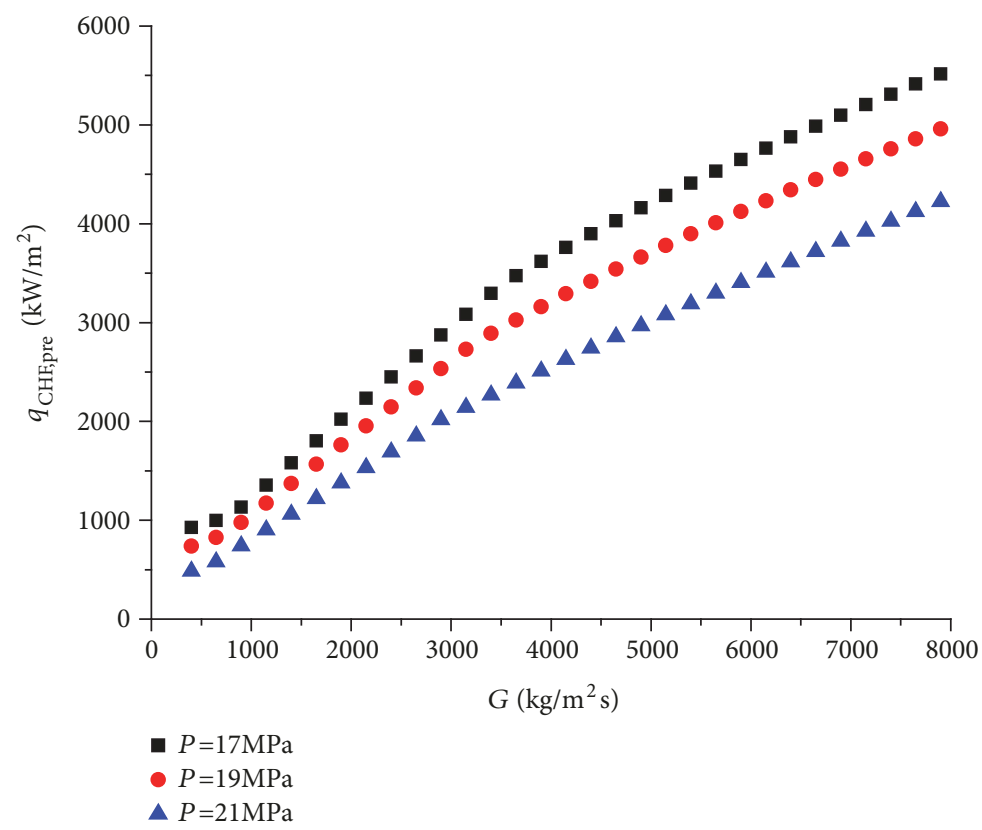

FIGURE 11: CHF as a function of mass velocity $\left(\Delta h_{\mathrm{in}}=500 \mathrm{~kJ} / \mathrm{kg}\right)$.

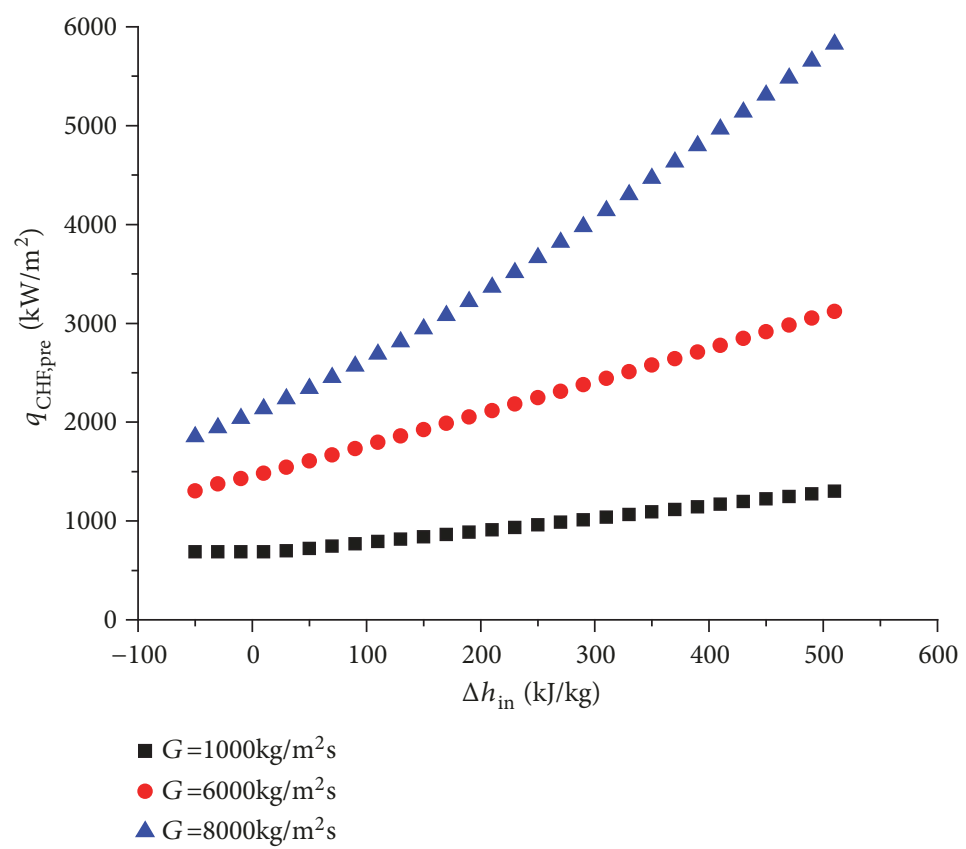

FIGURE 12: CHF as a function of inlet subcooled enthalpy ( $P=22 \mathrm{MPa})$.

quite similar to those for the conventional models, which are consistent with the physical mechanism and experimental phenomena.

\section{Nomenclature}

a: Empirical coefficient

$C$ : Concentration of droplets $\left(\mathrm{kg} / \mathrm{m}^{3}\right)$

$d$ : Hydraulic diameter $(\mathrm{m})$
$D: \quad$ Tube diameter $(\mathrm{m}) /$ droplet deposition rate $\left(\mathrm{kg} / \mathrm{m}^{2} \mathrm{~s}\right)$

$D_{b}$ : Vapour bubble diameter $(\mathrm{m})$

$E: \quad$ Entrainment rate $\left(\mathrm{kg} / \mathrm{m}^{2} \mathrm{~s}\right)$

$E_{w}$ : Wave droplet entrainment rate $\left(\mathrm{kg} / \mathrm{m}^{2} \mathrm{~s}\right)$

$E_{B}$ : Boiling droplet entrainment rate $\left(\mathrm{kg} / \mathrm{m}^{2} \mathrm{~s}\right)$

$G$ : Mass velocity $\left(\mathrm{kg} / \mathrm{m}^{2} \mathrm{~s}\right)$

$h$ : Enthalpy $(\mathrm{kJ} / \mathrm{kg})$

$h_{f g}$ : Latent heat of vaporization $(\mathrm{kJ} / \mathrm{kg})$ 


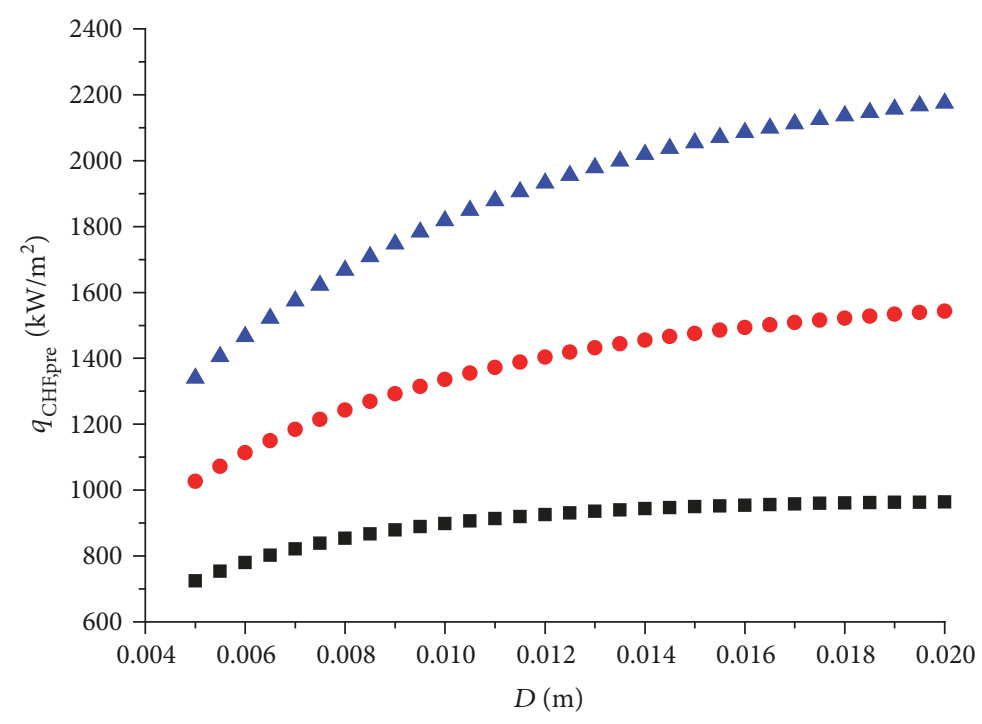

$$
\begin{aligned}
& \text { - } \Delta h_{\mathrm{in}}=100 \mathrm{~kJ} / \mathrm{kg} \\
& \text { - } \Delta h_{\mathrm{in}}=300 \mathrm{~kJ} / \mathrm{kg} \\
& \Delta \Delta h_{\mathrm{in}}=500 \mathrm{~kJ} / \mathrm{kg}
\end{aligned}
$$

FIGURE 13: $\mathrm{CHF}$ as a function of tube diameter $\left(P=17 \mathrm{MPa}, G=1000 \mathrm{~kg} / \mathrm{m}^{2} \mathrm{~s}, \mathrm{~L}=1 \mathrm{~m}\right)$.

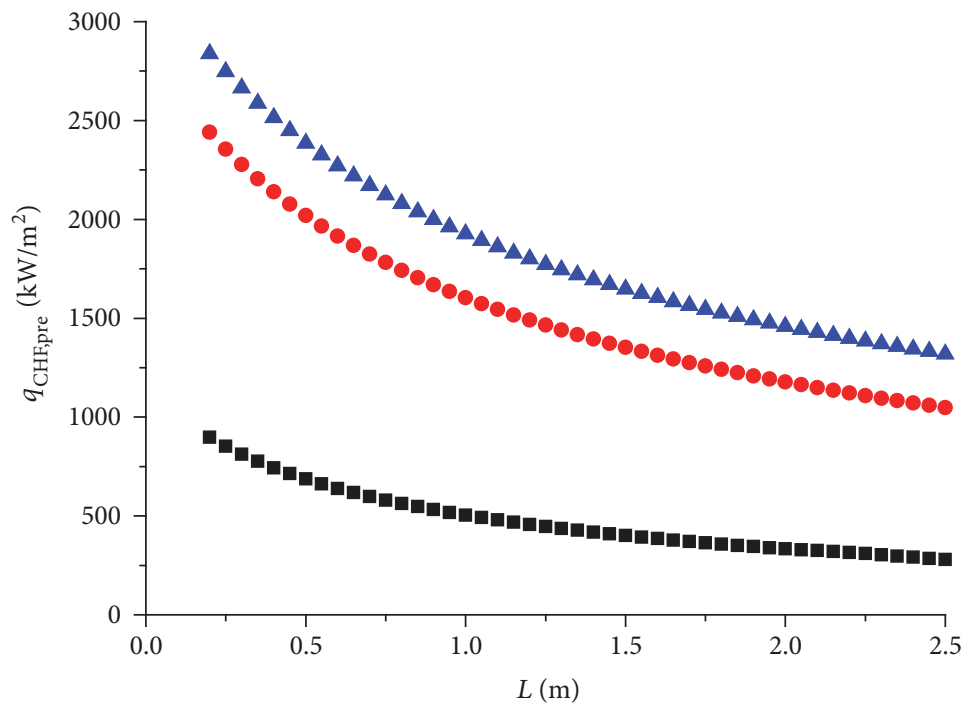

$$
\begin{aligned}
\text { - } G & =1000 \mathrm{~kg} / \mathrm{m}^{2} \mathrm{~s} \\
\text { - } G & =6000 \mathrm{~kg} / \mathrm{m}^{2} \mathrm{~s} \\
\text { - } G & =8000 \mathrm{~kg} / \mathrm{m}^{2} \mathrm{~s}
\end{aligned}
$$

Figure 14: CHF as a function of tube length ( $\left.P=21 \mathrm{MPa}, \Delta h_{\text {in }}=100 \mathrm{~kJ} / \mathrm{kg}, \mathrm{D}=0.008 \mathrm{~m}\right)$.

$h_{l d}$ : Enthalpy of liquid at the point of bubble detachment $(\mathrm{kJ} / \mathrm{kg})$

$j$ : Volumetric flux of superficial velocity $(\mathrm{m} / \mathrm{s})$

$k$ : Deposition mass transfer coefficient $(\mathrm{m} / \mathrm{s})$

$L: \quad$ Tube length $(\mathrm{m})$

P: Pressure $(\mathrm{MPa})$

q: Heat flux $\left(\mathrm{kW} / \mathrm{m}^{2}\right)$

Re: Reynolds number $u$ : Velocity $(\mathrm{m} / \mathrm{s})$

$x$ : Steam quality.

Greek Symbols

$\alpha$ : Void fraction

$\rho$ : Density $\left(\mathrm{kg} / \mathrm{m}^{3}\right)$

$\sigma$ : Surface tension $(\mathrm{N} / \mathrm{m})$

$\mu$ : Dynamic viscosity $(\mathrm{kg} / \mathrm{sm})$. 


\section{Subscripts}

ann: Annular

e: $\quad$ Equilibrium

$f$ : $\quad$ Fluid

g: $\quad$ Gas

pre: Predictive value

exp: Experimental value

in: Inlet conditions

sub: Subcooled conditions

v: Vapour

$l$ : $\quad$ Liquid

$L F$ : Liquid film

LFC: Critical liquid film mass velocity.

\section{Data Availability}

The CHF data in upflow boiling vertical round tube under high pressure supporting this manuscript 3695685 are from previously reported studies and datasets, which have been cited at relevant places within the text as references. The processed data are available from the published journal article or reports.

\section{Conflicts of Interest}

The authors declare that they have no conflicts of interest.

\section{Acknowledgments}

The authors would like to express their appreciation to Nuclear Power Institute of China for their financial support.

\section{References}

[1] J. Shan, J. Pan, and Y. Jiang, "Thermal consideration of CANDUSCWR sliding pressure startup through subchannel analysis," Nuclear Engineering and Design, vol. 240, no. 5, pp. 1005-1012, 2010.

[2] D. C. Groeneveld, "The critical heat flux story [C], The 15th International Topical Meeting on Nuclear Reactor Thermal Hydraulics," Pisa, Italy, 2013.

[3] L. S. Tong, "Heat transfer in water-cooled nuclear reactors," Nuclear Engineering and Design, vol. 6, no. 4, pp. 301-324, 1967.

[4] Y. Katto and H. Ohno, "An improved version of the generalized correlation of critical heat flux for the forced convective boiling in uniformly heated vertical tubes," International Journal of Heat and Mass Transfer, vol. 27, no. 9, pp. 1641-1648, 1984.

[5] R. W. Bowring, A Simple but Accurate Round Tube, Uniform Heat Flux, Dryout Correlation over Pressure Range 0.7$17 \mathrm{MN} / \mathrm{m}^{2}$ (100-2500psia), AEEW-R-789, UK Atomic Energy Authority, Winfrith, England, UK, 1972.

[6] D. D. Hall and I. Mudawar, "Critical heat flux for water flow in tubes-II: Subcooled CHF correlations," International Journal of Heat and Mass Transfer, vol. 43, no. 14, pp. 2605-2640, 2000.

[7] G. V. Alekseev and B. A. Zenkevich, "Burn-out heat fluxes under forced water flow," in Proceedings of the Third United Nations International Conference on the Peaceful Uses of Atomic Energy, May 1964.
[8] D. C. Groeneveld, J. Q. Shan, A. Z. Vasić et al., “The 2006 CHF look-up table," Nuclear Engineering and Design, vol. 237, no. 1517, pp. 1909-1922, 2007.

[9] J. Weisman and B. S. Pei, "Prediction of critical heat flux in flow boiling at low qualities," International Journal of Heat and Mass Transfer, vol. 26, no. 10, pp. 1463-1477, 1983.

[10] P. B. Whalley, P. Hutchinson, and G. F. Hewitt, "The calculation of critical heat flux in forced convection boiling," in Proceedings of the 5th International Heat Transfer Conference, Tokyo, Japan, 1974.

[11] I. Kataoka, M. Ishii, and A. Nakayama, "Entrainment and desposition rates of droplets in annular two-phase flow," International Journal of Heat and Mass Transfer, vol. 43, no. 9, pp. 1573-1589, 2000.

[12] I. I. Paleev and B. S. Filippovich, "Phenomena of liquid transfer in two-phase dispersed annular flow," International Journal of Heat and Mass Transfer, vol. 9, no. 10, pp. 1089-1093, 1966.

[13] M. Ishii and K. Mishima, "Droplet entrainment correlation in annular two-phase flow," International Journal of Heat and Mass Transfer, vol. 32, no. 10, pp. 1835-1846, 1989.

[14] G. P. Celata, K. Mishima, and G. Zummo, "Critical heat flux prediction for saturated flow boiling of water in vertical tubes," International Journal of Heat and Mass Transfer, vol. 44, no. 22, pp. 4323-4331, 2001.

[15] I. Kataoka and M. Ishii, "Entrainment and deposition rates of droplets in annular two phase flow," in Proceedings of the ASME/JSME Thermal Engineering Joint Conference, Y. Mori and W. J. Yang, Eds., vol. 1, 1983.

[16] G. F. Hewitt and A. H. Govan, "Phenomenological modelling of non-equilibrium flows with phase change," International Journal of Heat and Mass Transfer, vol. 33, no. 2, pp. 229-242, 1990.

[17] H. McGill and W. L. Sibbitt, Heat Transfer and Pressure Drop of Water Flowing in a Small Tube, ANL-4603 (Part I), Argonne National Laboratory, Argonne, Ill, USA, 1951.

[18] H. M. Epstein, J. W. Chastain, and S. L. Fawcett, "Heat transfer and burnout to water at high subcirtical pressures," Report No: BMI-1116, Battelle Memorial Institute, Columbus, Ohio, USA, 1956.

[19] A. P. Ornatskii and A. M. Kichigin, "Critical heat loads in highpressure boiling of underheated water in small diameter tubes," Teploenergetika, vol. 9, no. 6, pp. 44-47, 1962.

[20] A. P. Ornatskii, "Critical heat loads and heat transfer for a forced flow of water in tubes in the region of superhigh pressures (175220 atm)," Teploenergetika, vol. 10, no. 3, pp. 66-69, 1963.

[21] G. V. Alekseev, B. A. Zenkevich, O. L. Peskov et al., "Burnout heat fluxes under forced water flow," in Proceeding of the International Conference on the Peaceful Uses of Atomic Energy, International Atomic Energy Agency, pp. 295-304, Vienna, Austria, 1964.

[22] N. A. Bailey and D. H. Lee, "An experimental and analytical study of boiling water at 2000 to 2600 psi," Part I. Dryout and Post-Dryout Heat Transfer, AEEW-R659, 1969.

[23] O. L. Peskov, V. I. Subbotin, B. A. Zenkevich et al., "The critical heat flux for the flow of steam-water mixtures through pipes," in Problems of Heat Transfer and Hydraulics of Two-Phase Media, pp. 48-62, Pergamon Press, Oxford, UK, 1969.

[24] B. A. Zenkevich, O. L. Peskov, N. Petrishcheva et al., An Analysis and Correlation of the Experimental Data on Burnout in the Case of Forced Flow of Boiling Water in Pipes, Physics-Energy Institute, Atomizdat, Moscow, Russia, 1969. 
[25] B. A. Zenkevich, O. L. Peskov, and N. D. Sergeev, Burnout with forced flow of water in uniformly heated long tubes, IPPE-254, Institute of physics and power engineering, Obninsk, Russia, 1971.

[26] B. A. Zenkevich, "Analysis and generalization of experimental data on heat transfer crisis associated with forced convection of cooling water in tubes," AECL-Tr-Misc.-304, 1974.

[27] I. I. Belyakov, V. P. Lavrent'ev, S. N. Smirnov, and V. V. Sokolov, "Investigation of post-dryout in vertical tubes," TsKTI053501/0-9119, Tsentral'nyii Kotlo-Turbinnyii Institut (Central Boiler-Turbine Institute), Leningrad, Russia, 1976.

[28] V. N. Smolin, S. V. Shpansky, V. I. Esikov, and T. K. Sedova, "Experimental data and prediction of crisis in boiling water in tubes (for uniform and nonuniform heat flux)," roblems of Atomic Science and Engineering-Physics and Engineering of Nuclear Reactors, vol. 5, no. 9, pp. 3-154, 1979.

[29] C. Williams and S. Beus, "Critical heat flux experiments in a circular tube with heavy water and light water (AWBA Development Program)," WAPD-TM-1462, Westinghouse Electric Corp, Pittsburgh, PA, USA, 1980.

[30] P. L. Kirillov, O. L. Peskov, and N. P. Serdun', "Control experiment on critical heat transfer during water flow in pipes," Soviet Atomic Energy, vol. 57, no. 6, pp. 858-860, 1984.

[31] D. C. Groeneveld, "The onset of dry sheath condition - A new definition of dryout," Nuclear Engineering and Design, vol. 92, no. 2, pp. 135-140, 1986.

[32] S. T. Yin, T. J. Liu, Y. D. Huang, and R. M. Tain, "Measurements of critical heat flux in forced flow at pressures up to the vicinity of the critical point of water," in Proceedings of the 25th National Heat Transfer Conference, vol. 2, pp. 501-506, Houston, USA, 1988.

[33] B. Soderquist, Swedish CHF Data Received via Personal Communication with Groeneveld D.C, Department of Nuclear Reactor Engineering, Stockholm, March 1994.

[34] I. Mudawar and M. B. Bowers, "Ultra-high critical heat flux (CHF) for subcooled water flow boiling-I: CHF data and parametric effects for small diameter tubes," International Journal of Heat and Mass Transfer, vol. 42, no. 8, pp. 1405-1428, 1999. 

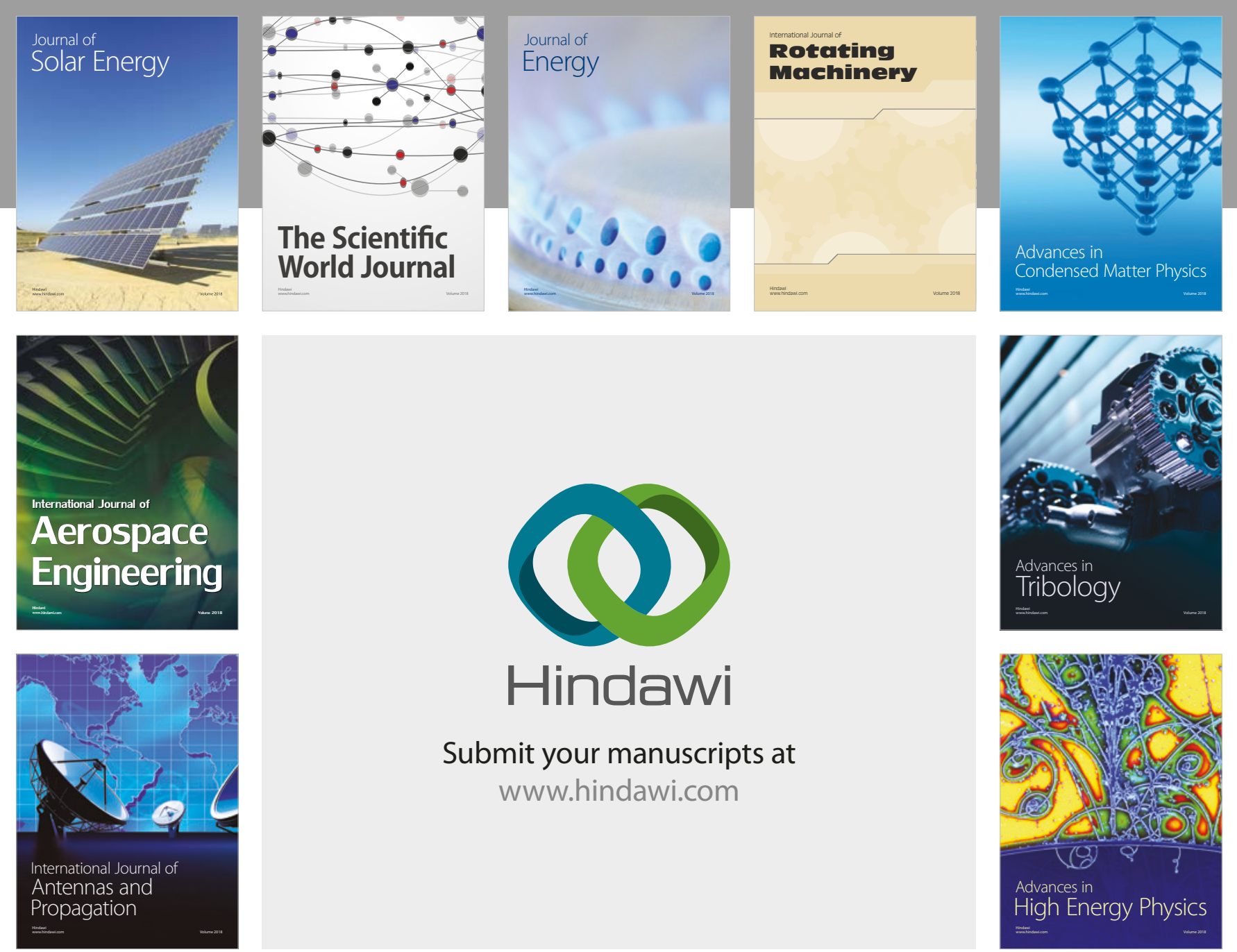

Submit your manuscripts at

www.hindawi.com
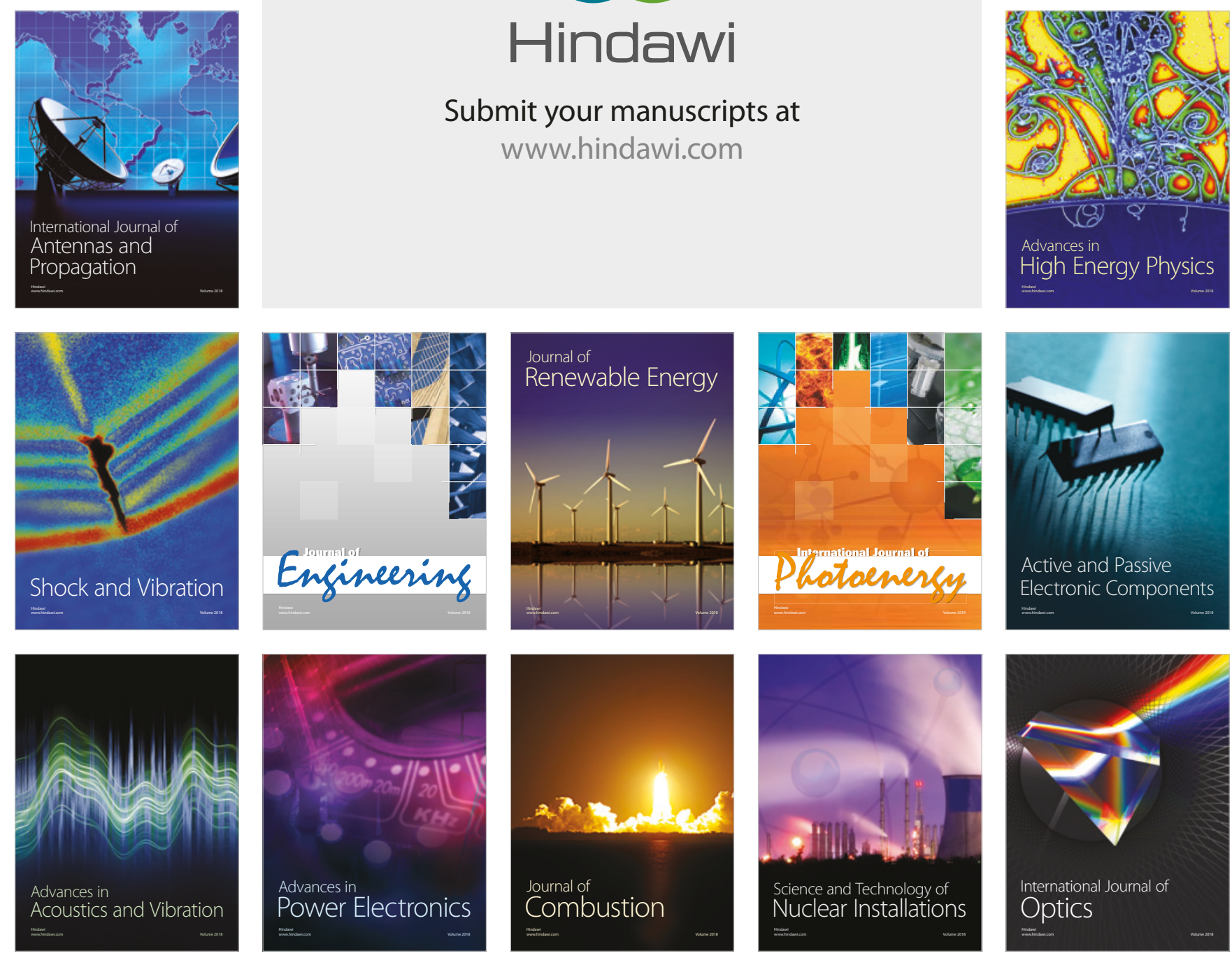